\title{
Comparison of obstetric outcomes between on-call and patients' own obstetricians
}

\author{
Haim A. Abenhaim MD MPH, Alice Benjamin MD, Robert D. Koby MD, Robert A. Kinch MD, \\ Michael S. Kramer MD
}

$\infty$

See related article page 372

\section{ABSTRACT}

Background: The question "will you be delivering my baby?" is one that pregnant women frequently ask their physicians. We sought to determine whether obstetric outcomes differed between women whose babies were delivered by their own obstetrician (regular-care obstetrician) and those attended by an on-call obstetrician who did not provide antenatal care.

Methods: We performed a cohort study of all live singleton term births between 1991 and 2001 at the Royal Victoria Hospital in Montréal. We excluded breech deliveries, elective cesarean sections and deliveries with placenta previa or prolapse of the umbilical cord. Logistic regression analysis was used to compare obstetric outcomes (e.g., cesarean delivery, instrumental vaginal delivery and episiotomy) between the regular-care and on-call obstetricians after adjustment for potential confounders.

Results: A total of 28332 eligible deliveries were attended by 26 obstetricians: 21779 (76.9\%) by the patient's own obstetrician and $6_{553}(23.1 \%)$ by the on-call obstetrician. Compared with women attended by their regular-care obstetrician, those attended by an on-call obstetrician had higher rates of cesarean delivery ( $11.9 \%$ v. $11.4 \%$, adjusted odds ratio [OR] $1.13,95 \%$ confidence interval [Cl] 1.03-1.24, $p<0.01$ ) and of third- or fourth-degree tears (7.9\% v. $6.4 \%$, adjusted $\mathrm{OR} 1.21,95 \% \mathrm{Cl} 1.07-1.36, p<0.01)$ but lower rates of episiotomy (38.5\% v. $42.9 \%$, OR $0.77,95 \% \mathrm{Cl} 0.72-0.82$, $\mathrm{p}<0.001)$. No differences were observed between the groups in the rate of instrumental vaginal delivery. The increase in the overall rate of cesarean delivery among women attended by an on-call obstetrician was due mainly to an increase in cesarean deliveries during the first stage of labour because of nonreassuring fetal heart tracing (2.9\% v. 1.7\%, adjusted OR 1.79, 95\% Cl 1.49-2.15, $p<0.001)$. The time of day of delivery did not modify the observed effects.

\section{Interpretation: The type of attending obstetrician (regular care v. on call) had a minor effect on obstetric outcomes.}

Une version française de ce résumé est disponible à l'adresse www.cmaj.ca/cgi/content/full/I77/4/352/DCI

CMAJ 2007;177(4):352-6
$\mathrm{T}$ he practice of obstetrics has changed considerably over the last several decades. In addition to the improvements in obstetric outcomes because of prenatal surveillance and treatments, the provision of obstetric care has also changed. The 24-hour availability of obstetricians that was typical in the past has evolved into a rotating call system, which, in addition to ensuring round-the-clock coverage, allows obstetricians to have a more predictable lifestyle and may reduce the number of medical errors..$^{1-5}$ With these changes, however, there has been an increase in concern about quality of care. The question "will you be delivering my baby?" is frequently asked by pregnant women, which is understandable considering the comfort that comes with seeing one's own doctor in the labour and delivery setting. However, little is known about the differences in obstetric outcomes experienced by women attended by their own prenatal care provider compared with an on-call physician. It is well established that the doctor-patient relationship is strongly associated with medicolegal action, ${ }^{6,7}$ and it has been suggested that the medicolegal pressure felt by obstetricians is associated with the rise in cesarean delivery rates. ${ }^{8-10}$ In this study, we sought to determine whether obstetric outcomes differ between women attended by their own obstetrician and those attended by an on-call obstetrician.

\section{Materials and methods}

\section{Study design}

We carried out a hospital-based cohort study using the McGill Obstetrical and Neonatal Database. ${ }^{11}$ The database contains detailed obstetric and neonatal information on all infants weighing $500 \mathrm{~g}$ or more who were liveborn or stillborn at the Royal Victoria Hospital in Montréal. The data are coded by an archivist in the medical record room (who works full time with this database) and, for cases needing special scrutiny, reviewed by a neonatologist or an obstetrician. The use of this database for research purposes was approved by

From the Department of Obstetrics and Gynecology (Abenhaim, Benjamin, Koby, Kinch), Royal Victoria Hospital, McGill University; and the Departments of Pediatrics, and Epidemiology and Biostatistics (Kramer), McGill University, Montréal, Que. 
the Director of Professional Services and the Institutional Review Board of the McGill University Health Centre.

The Royal Victoria Hospital, a tertiary care teaching hospital affiliated with McGill University, has a 24-hour on-call system in the birthing centre year round. Most obstetricians attend their own patients' deliveries, but they may sign out the care of their patients to the on-call obstetrician at any time. Women receive their prenatal care from a single obstetrician. No family physicians or midwives provide prenatal care or perform deliveries at the Royal Victoria Hospital.

\section{Study population}

The study population included all live singleton term births between Apr. I, I99I, and Mar. 3I, 200I. We excluded multifetal pregnancies, breech presentations, preterm births ( $<37$ weeks) and elective cesarean deliveries. We also excluded cases if the decision for nonelective cesarean delivery was made because of placenta previa or prolapse of the umbilical cord. We included only deliveries made by physicians who had followed and attended a minimum of roo women at the study hospital during the study period. Deliveries were categorized as being either attended by the women's own obstetrician (obstetrician who followed the patient throughout the pregnancy; herein referred to as regular-care obstetrician) or by a different obstetrician (oncall obstetrician).

\section{Outcomes}

Information on potential confounders was identified and categorized chronologically as antepartum, intrapartum or neonatal. We compared the baseline characteristics and obstetric outcomes of women attended by their regular-care obstetrician with those of women attended by an on-call obstetrician. We stratified the analysis by stage of labour at delivery (first stage, cesarean birth before full dilatation; second stage, cesarean or vaginal birth at full dilatation) and by time of day of the delivery. We calculated the rate of first-stage cesarean deliveries using all deliveries as the denominator, and we calculated the rate of second-stage cesarean deliveries using second-stage deliveries only as the denominator. (First-stage cesarean deliveries could not be included in the latter analysis because these women are, by definition, not at risk of secondstage cesarean section). Time of day of delivery was stratified as day (7 am-7 pm) or night (7 pm-7 am). Indications for cesarean birth were categorized as dystocia, nonreassuring fetal heart tracing, cesarean sections with trial of labour, or "other" as determined and documented by the obstetrician at the time of cesarean section (included failed induction, prolonged membrane rupture and maternal indications [e.g., worsening pre-eclampsia, hemodynamic instability]).

\section{Statistical analysis}

We performed both crude and adjusted unconditional logistic regression analyses and obtained odds ratios (ORs) and $95 \%$ confidence intervals (CIs) as an estimate of relative risk. The adjusted model included the following continuous variables: maternal age, gestational age and birth weight. The categorical variables included in the model were gestational and pre-existing diabetes, previous cesarean delivery, multi- parity, body mass index before pregnancy greater than $30 \mathrm{~kg} / \mathrm{m}^{2}$, induction of labour, oxytocin use, epidural use and smoking. To account for temporal changes in practice patterns, we included an additional variable that specified whether the delivery had occurred during either the first 5 years or the second 5 years of the study period. An OR greater than I represents an increase in an outcome among on-call obstetricians compared with regular-care obstetricians, and an OR less than I represents a decrease. We also examined obstetric outcomes after stratifying the data by stage of labour and time of delivery. Statistical analyses were 2-tailed, at a significance level of 0.05 .

\section{Results}

We identified a total of 36756 deliveries that took place during the Io-year study period, of which 28332 (77.I\%) were attended by 26 obstetricians who met the selection criteria. Regular-care

Table 1: Characteristics of 21799 deliveries attended by the woman's regular-care obstetrician and 6553 deliveries attended by an on-call obstetrician who did not provide antenatal care

\begin{tabular}{|c|c|c|}
\hline \multirow[b]{2}{*}{ Characteristic } & \multicolumn{2}{|c|}{ Obstetrician type; \% of deliveries* } \\
\hline & $\begin{array}{c}\text { Regular care } \\
n=21779\end{array}$ & $\begin{array}{c}\text { On call } \\
n=6553\end{array}$ \\
\hline \multicolumn{3}{|l|}{ Maternal } \\
\hline Age, yr, mean (SD) & $30.8(4.9)$ & $30.2(4.9)$ \\
\hline Smoking & 15.7 & 17.9 \\
\hline Multiparous & 51.9 & 49.3 \\
\hline $\begin{array}{l}\text { Body mass index } \\
\geq 30 \mathrm{~kg} / \mathrm{m}^{2}\end{array}$ & 11.5 & 10.4 \\
\hline $\begin{array}{l}\text { Previous cesarean } \\
\text { section }\end{array}$ & 6.3 & 6.7 \\
\hline $\begin{array}{l}\text { Pre-existing diabetes } \\
\text { mellitus }\end{array}$ & 0.5 & 0.2 \\
\hline Gestational diabetes & 5.4 & 3.7 \\
\hline Pre-eclampsia & 2.7 & 2.0 \\
\hline \multicolumn{3}{|l|}{ Gestational age, wk } \\
\hline $37-38+6$ & 27.5 & 28.2 \\
\hline $39-40+6$ & 56.2 & 57.1 \\
\hline$\geq 41$ & 16.3 & 14.6 \\
\hline \multicolumn{3}{|l|}{ Intrapartum } \\
\hline Induction of labour & 32.5 & 13.7 \\
\hline Use of oxytocin & 65.8 & 52.7 \\
\hline $\begin{array}{l}\text { Use of epidural } \\
\text { analgesia }\end{array}$ & 77.3 & 71.4 \\
\hline \multicolumn{3}{|l|}{ Neonatal } \\
\hline \multicolumn{3}{|l|}{ Birth weight, g } \\
\hline$<2500$ & 1.4 & 1.8 \\
\hline $2500-3999$ & 85.7 & 87.3 \\
\hline$\geq 4000$ & 12.8 & 10.9 \\
\hline
\end{tabular}

Note: $\mathrm{SD}=$ standard deviation.

*Unless stated otherwise. 
obstetricians attended 2I 779 (76.9\%) deliveries and on-call obstetricians attended 6553 (23.1\%). Fifty-three percent ( 15 000/28 332) of included deliveries took place between $7 \mathrm{am}$ and $7 \mathrm{pm}$. Labour lasted longer in the group managed by regular-care obstetricians than in the group managed by on-call obstetricians ( 557 minutes v. 539 minutes, $p<0.001$ ). Deliveries attended by regular-care obstetricians were more likely than those attended by on-call obstetricians to be induced, to require oxytocin and to require epidural analgesia (Table I). No differences were observed in birth-weight categories or mean birthweight between the 2 groups.

The overall rate of cesarean deliveries was II.5\% (3262/28 332). We observed a small but statistically significant overall increase in the likelihood of cesarean deliveries (adjusted OR I.I3, 95\% CI I.03-I.24, $p<0.01$ ) among women attended by an on-call obstetrician compared with those attended by their regular-care obstetrician (Figure I, Appendix I [available online at www.cmaj.ca/cgi/content/full/177/4/352 /DC2]). This increase was most notable for cesarean deliveries performed because of nonreassuring fetal heart tracing (adjusted OR I.73, 95\% CI I.45-2.07, p < 0.00I). Among woman who had a vaginal delivery, those attended by an oncall obstetrician than were less likely than those attended by their regular-care obstetrician to have an episiotomy (adjusted OR $0.77,95 \% \mathrm{CI} 0.72-0.82, p<0.00 \mathrm{I}$ ) but were more likely to experience a third- or fourth-degree perineal tear (adjusted OR I.2I, 95\% CI I.07-I.36, $p<0.01$ ). There was no significant difference in the frequency of extraction using forceps or vacuum between the 2 groups.

Overall, 9.5\% (2684/28 332) of deliveries were performed by cesarean section in the first stage of labour, compared with $2.0 \%(578 / 28332)$ in the second stage of labour. The increase in the overall rate of cesarean deliveries among women attended by on-call obstetricians was primarily due to an increase in first-stage cesarean deliveries because of nonreassuring fetal heart tracing. Specifically, women attended by an on-call obstetrician were more likely than women attended by their regular-care obstetrician to have a first-stage cesarean delivery because of nonreassuring fetal heart tracing (adjusted OR I.79, 95\% CI I.49-2.15, $p<0.00$, Table 2, Appendix 2 [available online at www.cmaj.ca/cgi/content/full /I77/4/352/DC2]). In contrast, during the second stage of labour, there was no significant difference in the frequency of cesarean deliveries or indications between the 2 groups. There was no difference in outcome when the data were stratified by time of day (data not shown).

\section{Interpretation}

Our results suggest that, after adjustment for confounding variables, women attended by an on-call obstetrician are at increased risk of cesarean delivery or of third- or fourth-degree perineal tearing and are at decreased risk of episiotomy.

One possible explanation for the increased risk of cesarean delivery among women attended by on-call obstetricians is that on-call obstetricians may intervene sooner than an obstetrician who has provided the woman's prenatal care. Obstetricians may not want to delay what they consider to be a safe intervention if they do not have a pre-existing rapport with the woman. We noted a small, although statistically sig-

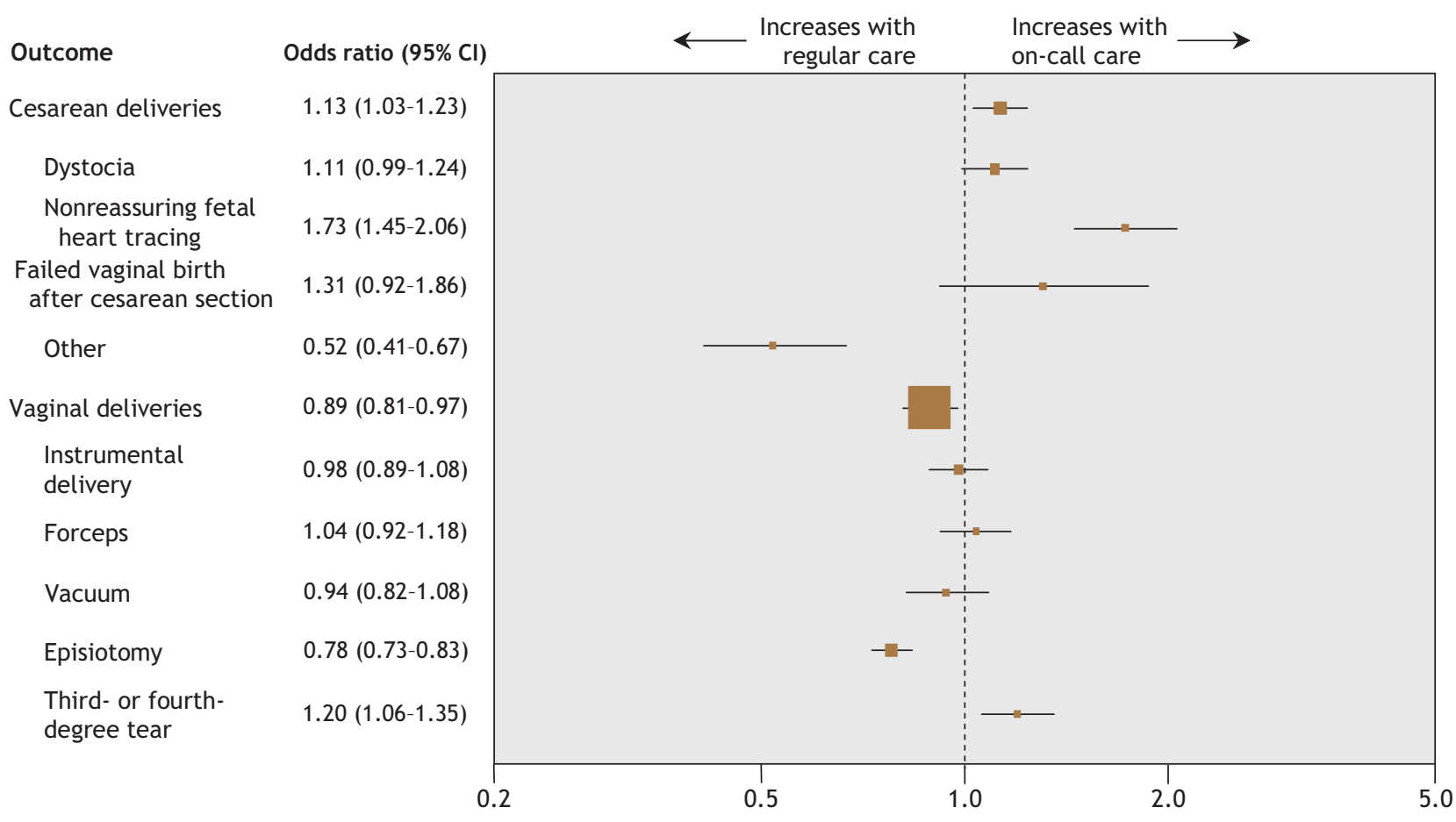

Figure 1: Forest plot showing the odds ratios for cesarean and vaginal deliveries attended by on-call obstetricians. 
Table 2: Proportion of cesarean deliveries attended by regular-care and on-call obstetricians, by stage of labour and indication

\begin{tabular}{|c|c|c|c|c|c|}
\hline Stage of labour & \multicolumn{2}{|c|}{ Obstetrician type; $\%$ of deliveries } & Crude OR $(95 \% \mathrm{Cl})$ & Adjusted* OR $(95 \% \mathrm{Cl})$ & $p$ value \\
\hline First stage $\dagger$ & $n=2049$ & $n=646$ & & & \\
\hline All indications & 9.4 & 9.8 & $1.05(0.96-1.15)$ & $1.14(1.03-1.26)$ & 0.02 \\
\hline Dystocia & 5.7 & 5.4 & $0.95(0.84-1.07)$ & $1.08(0.95-1.22)$ & 0.27 \\
\hline $\begin{array}{l}\text { Failed vaginal birth after } \\
\text { cesarean section }\end{array}$ & 0.5 & 0.7 & $1.33(0.94-1.88)$ & $1.47(1.01-2.14)$ & 0.04 \\
\hline Other & 1.4 & 0.7 & $0.49(0.36-0.67)$ & $0.42(0.30-0.57)$ & $<0.001$ \\
\hline Second stage $\neq$ & $n=19730$ & $n=5907$ & & & \\
\hline All indications & 2.2 & 2.3 & $1.03(0.85-1.25)$ & $1.15(0.94-1.41)$ & 0.18 \\
\hline Other & 0.1 & 0.1 & $0.93(0.34-2.50)$ & $0.97(0.35-2.67)$ & 0.97 \\
\hline
\end{tabular}

Note: $\mathrm{OR}=$ odds ratio, $\mathrm{Cl}=$ confidence interval.

*Adjusted for maternal age, parity, body mass index $\geq 30 \mathrm{~kg} / \mathrm{m}^{2}$, smoking, previous cesarean section, pre-existing and gestational diabetes, pre-eclampsia, induction of labour, use of oxytocin, use of epidural analgesia, gestational age, birth weight and first or second 5 years of the study period.

tPercentage of all deliveries.

$\ddagger$ Percentage of second-stage deliveries only.

nificant, difference in the mean duration of labour among the 2 groups. However, when duration of labour was adjusted for in the regression analysis, the magnitude of association between cesarean delivery and type of obstetrician did not change, which suggests that duration of labour probably had little or no effect on why on-call obstetricians were more likely to perform a cesarean delivery.

In our analysis, the main factor that contributed to the difference in the overall rate of cesarean section between the oncall and regular-care obstetricians appeared to be the difference in the rate of cesarean deliveries performed because of nonreassuring fetal heart tracing. The increased rate of cesarean deliveries for nonreassuring fetal heart tracing performed by on-call obstetricans may be the result of their presence in or near the labour and delivery ward. We attempted to adjust for this potential confounding variable by excluding acute conditions (i.e., cord prolapse and placenta previa).

Another explanation for our results could be the fear of medical malpractice. The recent increase in cesarean delivery for maternal and fetal indications has been temporally accompanied by a clear reduction in maternal and fetal morbidity and mortality. ${ }^{12-14}$ With rising concern over medical malpractice, obstetricians may practise "safer medicine" (i.e., the more liberal use of cesarean delivery) when faced with highrisk situations..$^{8-10,15,16}$ The same can be argued for the reduced use of episiotomies, which are thought to be associated with long-term maternal sequelae. ${ }^{17-19}$ Obstetricians may therefore manage labour and delivery differently for women who are not under their regular care (i.e., more cesarean deliveries and fewer episiotomies), especially given that most malpractice cases result from poor communication and a lack of trust between physician and patient $\mathrm{t}^{10,20}$ and given that communication and trust may be difficult to establish when meeting a patient for the first time.

In a study that examined the relation between on-call obstetricians and delivery outcomes, Goldberg and colleagues evaluated obstetric coverage by in-house and out-of-house on-call physicians. ${ }^{2}$ The authors concluded that patient management was not significantly affected by whether the attending physician was based in house or out of house. They observed an impressive difference in the rate of cesarean deliveries between in-house and out-of-house physicians (26.7\% v. 21.8\%); however, their results may have been influenced by the small sample (I20 deliveries by in-house physicians v. IIo deliveries by out-of-house physicians).

Our study has several limitations. First, our study design was retrospective and the information used, although routinely collected, was not obtained specifically for this study. Consequently, this may have resulted in misclassifications; however, the fact that our exposure (on-call or regular-care obstetrician present at the delivery) and outcomes were straightforward variables systematically entered in the database by the attending physician at the time of delivery reduced the possibility of missing data and misclassification. Furthermore, all collected data are verified by the database archivist, and periodic audits are conducted for quality assurance. A second limitation is that, in our institution, obstetric care is provided strictly by obstetricians; thus, our results may not be applicable to obstetric care provided by family physicians.

In interpreting our results, it is important to emphasize that deliveries attended by a woman's own obstetrician may be inherently different from deliveries attended by other obstetri- 
cians. We accounted for this potential source of confounding by excluding of deliveries with characteristics that, in our institution, would be certain to result in management by the attending physician (i.e., elective cesarean delivery, multifetal pregnancy and breech presentation). Current management of women with these characteristics at our institution is largely by cesarean section; thus, the inclusion of these deliveries would have diluted any association between the type of obstetrician and delivery outcomes. We also excluded cases of cord prolapse, because they are more likely to require urgent cesarean delivery, often by the in-house on-call obstetrician. We also accounted for potential sources of confounding by multivariable adjustments. Small differences were observed among on-call and regular-care obstetricians with respect to induction of labour and use of oxytocin and epidural anesthesia. These variables are well recognized as determinants of the rate of cesarean and instrumental deliveries. ${ }^{21-25}$ Although we included these and other potential confounders in our analysis, we cannot exclude residual confounding; their exclusion would require a randomized trial, which is unlikely to be acceptable to pregnant women or to obstetricians.

In conclusion, delivery by an on-call obstetrician, rather than by a regular-care obstetrician, was associated with a slightly increased risk of cesarean delivery and severe perineal laceration and a decreased risk of episiotomy. Although the precise mechanisms underlying the association between obstetrician type and these outcomes are unclear, it is important to emphasize that the magnitude of these associations is modest.

This article has been peer reviewed.

Competing interests: None declared.

Contributors: Haim Abenhaim, Alice Benjamin, Robert Koby and Robert Kinch conceived the study and its design. Haim Abenhaim and Michael Kramer performed the analysis and interpretation of data. All of the authors revised the article for important intellectual content and approved the final verson for publication.

\section{REFERENCES}

I. Borenstein SH, Choi M, Gerstle JT, et al. Errors and adverse outcomes on a surgical service: What is the role of residents? J Surg Res 2004;122:162-6.

2. Goldberg J, Gopal M, Singhal R, et al. Nighttime call in house vs. out of house: a comparison of obstetric procedure rates. J Reprod Med 2004;49:I43-7.
3. Jakubowicz DM, Price EM, Glassman HJ, et al. Effects of a twenty-four hour call period on resident performance during simulated endoscopic sinus surgery in an accreditation council for graduate medical education-compliant training program. Laryngoscope 2005;115:143-6.

4. Mann FA, Danz PL. The night stalker effect: quality improvements with a dedicated night-call rotation. Invest Radiol I993;28:92-6.

5. Scotti RJ. Compliance with the 24 -hour, in-house attending coverage requirement A survey. J Reprod Med I995;40:I0I-6.

6. Chauhan SP, Chauhan VB, Cowan BD, et al. Professional liability claims and Central Association of Obstetricians and Gynecologists members: myth versus reality. Am J Obstet Gynecol 2005;192:I820-6.

7. Tsai WC, Kung PT, Chiang YJ. Relationship between malpractice claims and medical care quality. Int J Health Care Qual Assur Inc Leadersh Health Serv 2004; I7: 394-400.

8. Dubay L, Kaestner R, Waidmann T. The impact of malpractice fears on cesarean section rates. J Health Econ I999;I8:49I-522.

9. Ryan K, Schnatz P, Greene J, et al. Change in cesarean section rate as a reflection of the present malpractice crisis. Conn Med 2005;69:I39-4I.

Io. Vimercati A, Greco P, Kardashi A, et al. Choice of cesarean section and perception of legal pressure. J Perinat Med 2000;28:III-7.

II. Fretts RC, Schmittdiel J, McLean FH, et al. Increased maternal age and the risk of foetal death. N Engl J Med I995;333:953-7.

I2. Black C, Kaye JA, Jick H. Cesarean delivery in the United Kingdom: time trends in the general practice research database. Obstet Gynecol 2005;I06:I5I-5.

I3. Meikle SF, Steiner CA, Zhang J, et al. A national estimate of the elective primary cesarean delivery rate. Obstet Gynecol 2005;105:75I-6.

I4. Tampakoudis P, Assimakopoulos E, Grimbizis G, et al. Cesarean section rates and indications in Greece: data from a 24-year period in a teaching hospital. Clin Exp Obstet Gynecol 2004;31:289-92.

I5. de Regt RH, Minkoff HL, Feldman J, et al. Relation of private or clinic care to the cesarean birth rate. $N$ Engl J Med ig86;315:619-24.

I6. Grant D, McInnes MM. Malpractice experience and the incidence of cesarean delivery: a physician-level longitudinal analysis. Inquiry 2004;41:170-88.

I7. Carroli G, Belizan J. Episiotomy for vaginal birth. Cochrane Database Syst Rev 2000; (2):CDoooo8I.

I8. Eason E, Feldman P. Much ado about a little cut: Is episiotomy worthwhile? Obstet Gynecol 2000;95:6r6-8.

I9. Hartmann K, Viswanathan M, Palmieri R, et al. Outcomes of routine episiotomy: a systematic review. JAMA 2005;293:214I-8.

20. Blackston JW, Bouldin MJ, Brown CA, et al. Malpractice risk prevention for primary care physicians. Am J Med Sci 2002;324:212-9.

2I. Decca L, Daldoss C, Fratelli N, et al. Labour course and delivery in epidural analgesia: a case-control study. J Matern Fetal Neonatal Med 2004;16:II5-8.

22. Gaiser RR. Labour epidurals and outcome. Best Pract Res Clin Anaesthesiol 2005;I9:I-I6.

23. Kaul B, Vallejo MC, Ramanathan S, et al. Induction of labour with oxytocin increases cesarean section rate as compared with oxytocin for augmentation of spontaneous labour in nulliparous parturients controlled for lumbar epidural analgesia. JClin Anesth 2004; 6 :4II-4.

24. Rogers R, Gilson GJ, Miller AC, et al. Active management of labour: Does it make a difference? Am J Obstet Gynecol I997;177:599-605.

25. White AA, Pichert JW, Bledsoe SH, et al. Cause and effect analysis of closed claims in obstetrics and gynecology. Obstet Gynecol 2005;105:1031-8.

Correspondence to: Dr. Haim A. Abenhaim, Department of Obstetrics and Gynecology, Hôpital Sainte-Justine, 3175 chemin de la Côte Sainte-Catherine, Montréal QC H3T IC5; fax 514 3454648; haim.abenhaim@gmail.com 